\title{
Statistics for Machining of high-strength materials
}

\author{
Zhiyuan $\mathrm{Wu}^{1, \mathrm{a}}$, Zhikun Tan ${ }^{1, \mathrm{~b}}$, Shuhui Wang ${ }^{2, \mathrm{c}}$, Xiaoqing Dong ${ }^{1, \mathrm{~d}}$ \\ ${ }^{1}$ National Key Laboratory for Equipment Remanufacturing, Academy of Armored Force \\ Engineering,P.R. China, 100072
}

${ }^{2}$ Department of Scientific Research, Academy of Armored Force Engineering, P.R. China, 100072

aWu_zhiyuan20021@163.com,,Tanzhikun2016@163.com, ' greenleaf999@163.com

Keywords: Impactive cutting, Orthogonal experiment, Deposited materials, Remanufacturing

\begin{abstract}
Through sorting and statistics of relevant test results on machining of high-strength materials at home and abroad, the tool materials and the distribution characteristics of tools' optimal geometric parameters as well as the possible causes are analyzed. The statistical results can be not only used as practical data for reference, but also used for selection on initial parameters for study on optimization of related processes, so that the test workload is reduced.
\end{abstract}

\section{Introduction}

Along with the development of modern mechanical industries like aerospace industry, weapon industry and nuclear industry, there are various high level requirements for properties of product part materials, and new materials like high-strength steel, ultra-high strength alloy steel and high manganese steel are springing up. Some materials are difficult to machine, which are called "difficult-to-machine materials" and include materials with high hardness, high strength, high ductility, high toughness, low plasticity and high brittleness.

The high-strength materials have the biggest characteristic of high hardness and strength and simultaneously are good in toughness and plasticity [1]. High-strength steel, ultrahigh-strength steel and high manganese steel are the most representative. The high-strength materials have the machining characteristics of being large in cutting force, high in cutting temperature and fast in tool wear [2], high in work hardening, strong in chemical affinity, easy in generation of tool sticking and good in friction effect of high hardness particles [3 5].

Through reading a large amount of data which shows that the high-strength material machining is mainly studied from aspects of tool material, tool angle and cutting data, as the data is dispersive as well as different when the study is performed in different directions, and no systematic data law is formed, experimental steps are repeated during high-strength material machining, so that the experiment workload is increased. Through sorting and statistics of relevant test results on machining of high-strength materials at home and abroad in the paper, the tool materials and the distribution characteristics of tool's optimal geometric parameters as well as the possible causes are analyzed, so that the systematic data law is formed.

\section{Tools for high-strength material machining}

At present, hard high-speed steel tool, alloy tool, ceramics tool and cubic boron nitride cutting tool are mainly used for machining. Due to low hardness, the high-speed steel tool is not suitable for high-strength material machining; we discovered in the process of reading the literature that the tool made of cubic boron nitride is rarely used for high-strength material machining due to insufficient hardness and bad toughness [6]. The tools for high-strength material machining are mainly made of hard alloy and ceramics, of which the use proportions are shown in Fig 1 and occupy $66.49 \%$ and $33.51 \%$ respectively. As the ceramics tool is more sensitive to vibration and vibration load, the hard alloy tool is higher that the ceramics tool in use proportion. The worse the vibration resistance of the ceramics tool is, the greater the vibration is, and the larger the possibility of tipping is. 


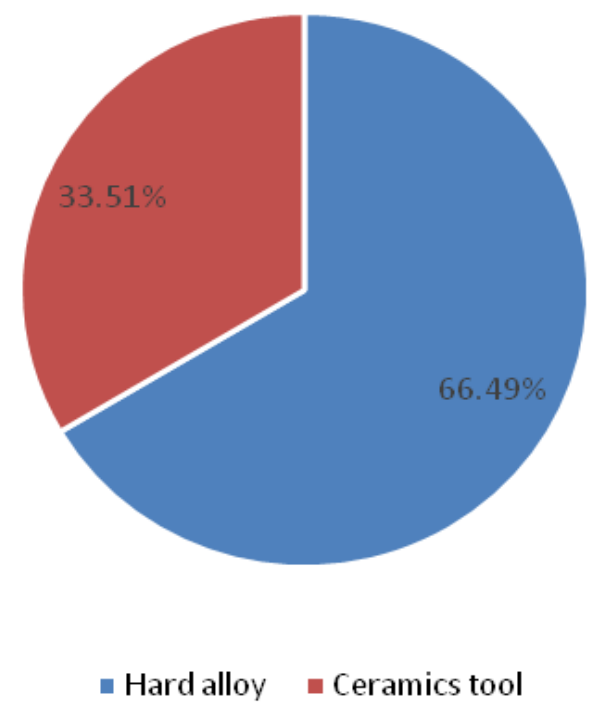

Fig. 1 Diagram for Use Proportions of Different Materials of Tools for High-strength Material Machining

\section{Parameters of tools for high-strength material machining}

After the tool is determined, its machinability is decided by its geometrical parameters. The geometrical parameters shall be reasonably selected according to concrete tool material, workpiece material and machining conditions, so that the tool machinability can be effectively realized.

Front rake angle. The larger the front rake angle is, the sharper the tool is; after the cutting force and the cutting temperature are reduced, built-up edges can be restrained or eliminated. However, the larger the front rake angle is, the lower the tool tip strength is, therefore, the smaller front rake angle shall be selected in high-strength material machining. Fig. 2 is the diagram for selection laws of front rake angles of different materials of tools for high-strength material machining:

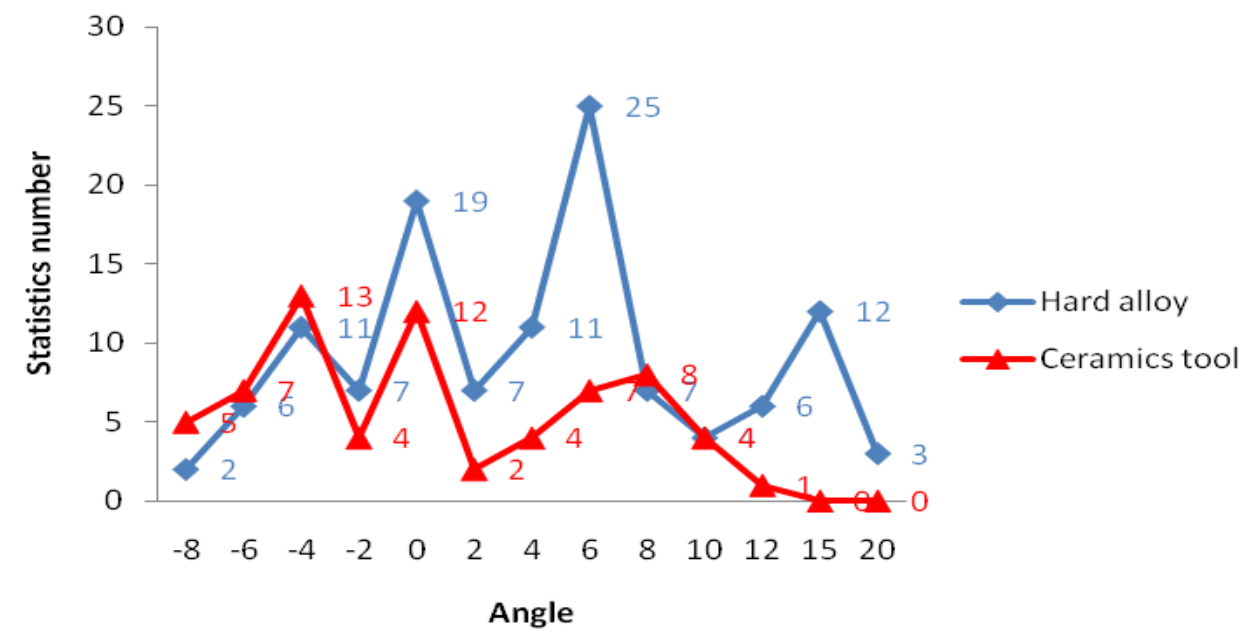

Fig. 2 Diagram for Selection Laws of Front Rakes Angles of Different Materials of Tools for High-strength Material Machining

Through analyzing the law diagram, we can obtain that in high-strength material machining, the section laws of the front rake angles of two types of tools are relatively disperse; the larger front rake angle $\gamma_{0}$ is mainly selected for the hard alloy tool, and generally, when $\gamma_{0}$ is $4^{\circ}-8^{\circ}$, the hard alloy tool occupies $37 \%$ in use proportion; the smaller negative front rake angle $\gamma_{0}$ can also be selected, and generally when $\gamma_{0}$ is $-4^{\circ}-0^{\circ}$, the hard alloy tool occupies $31 \%$ in use proportion. The smaller negative front rake angle $\gamma_{0}$ is selected for the ceramics tool, and generally, when $\gamma_{0}$ is 
$-4^{\circ}-0^{\circ}$, the ceramics tool occupies $37 \%$ in use proportion. The selection range of the hard alloy tool is wider than that of the ceramics tool, and the larger positive front rake angle cannot be selected for the ceramics tool due to bad vibration resistance, and the damage to the ceramics tool can be reduced if the smaller negative front rake angle is selected.

Relief angle. The main effects of the relief angle are to reduce the friction between the flank face and the workpiece and cooperate with the front rake angle to adjust the tool bit's sharpness and intensity, and meanwhile, the tool strength and heat dissipation area can also be affected. The selection laws of relief angles of two types of tools are shown as follows:

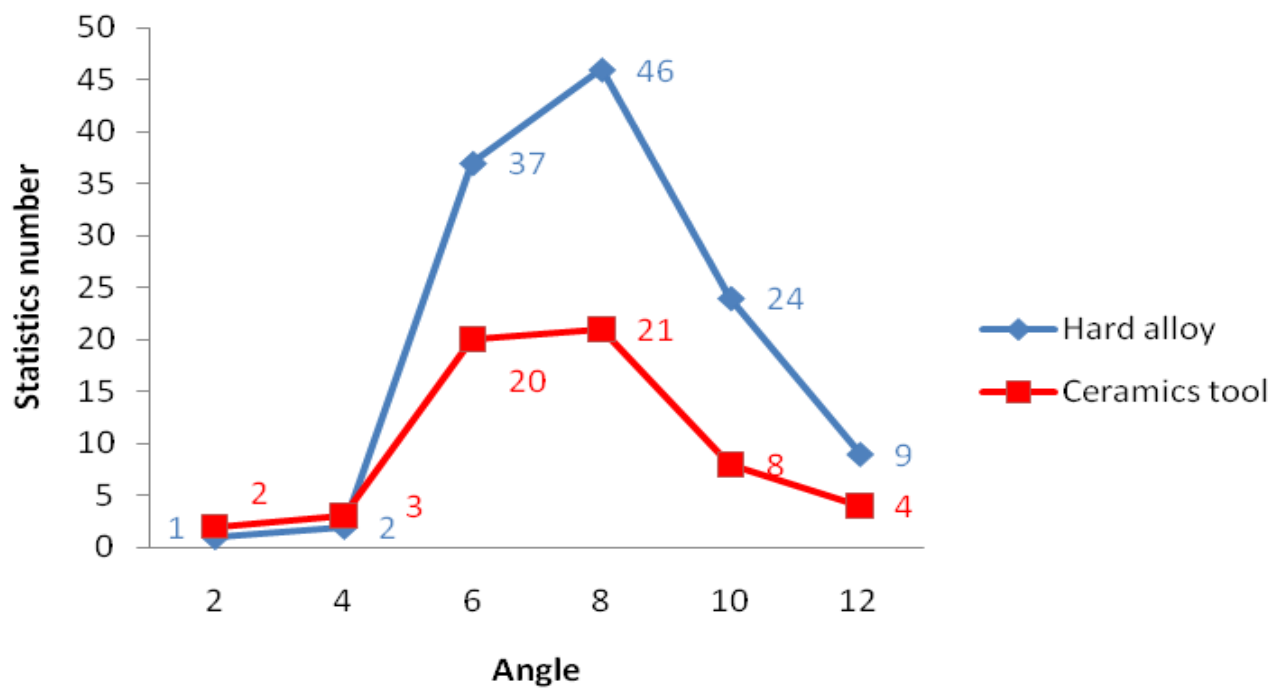

Fig. 3 Diagram for Selection Laws of Relief Angles of Two Types of Tools for High-strength Material Machining

Through analyzing the law diagram, we can obtain that in high-strength material machining, the hard alloy tool occupies $97 \%$ in use proportion when the relief angle $\alpha_{0}$ of $6^{\circ}-12^{\circ}$ is selected, the ceramics tool occupies $90 \%$ in use proportion when the relief angle $\alpha_{0}$ of $6^{\circ}-10^{\circ}$ is selected, and the respective relief angle $\alpha_{0}$ is consistent with that of $6^{\circ}-8^{\circ}$ of the common tool in selection range. The selected relief angles reach $8^{\circ}$ and accord with the normal distribution law, which shows that the optimal relief angle is $8^{\circ}$. The hard alloy tool is wider than that of the ceramics tool in relief angle selection range; as the larger relief angle can affect the impact resistance of the ceramics tool, the larger relief angle is inadvisably selected for the ceramics tool.

Cutting edge inclination angle. The flowing direction of cuttings can be controlled through controlling the cutting edge inclination angle. The impact resistance of the tool tip can be improved in case of selecting the negative cutting edge inclination angle. However, in case of selecting the larger cutting edge inclination angle, the radial cutting force can be obviously increased. The diagram for selection laws of cutting edge inclination angles of two types of tools is shown as follows: 


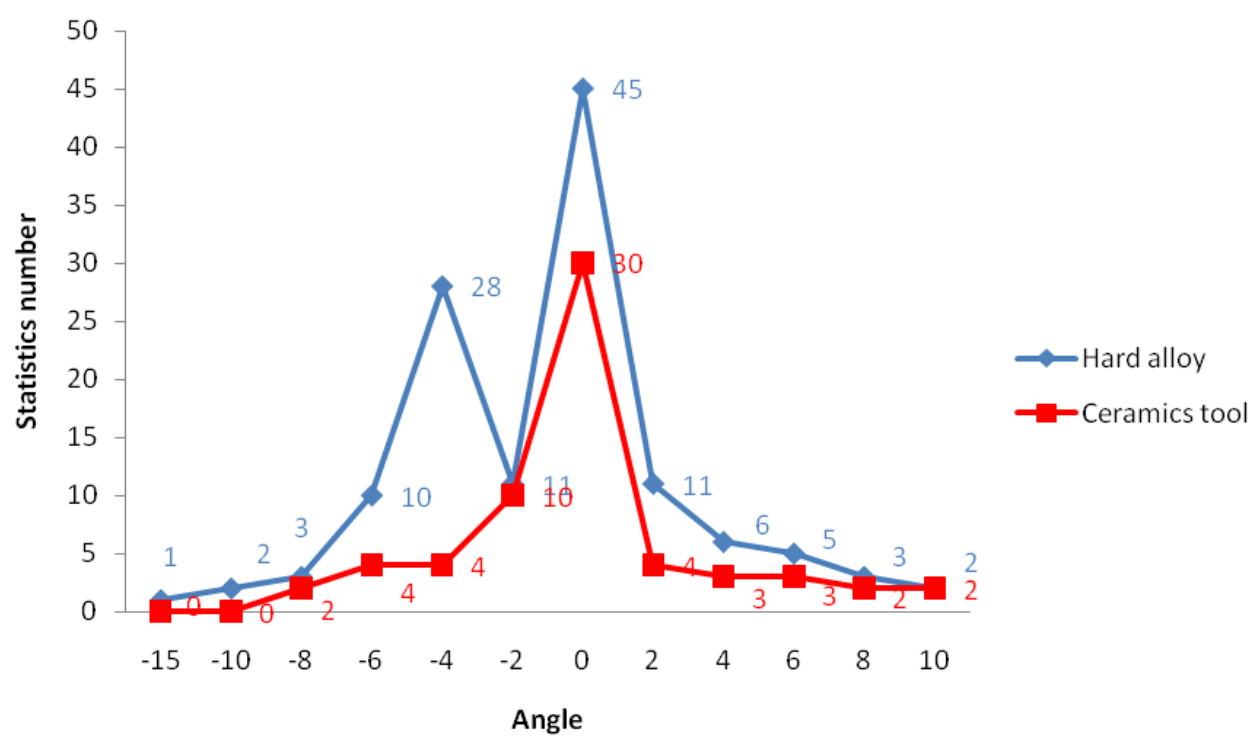

Fig. 4 Diagram for Selection Laws of Cutting Edge Inclination Angle of Two Types of Tools for High-strength Material Cutting

Through analyzing the law diagram, we can obtain that in high-strength material machining, the cutting edge inclination angles $\lambda \mathrm{s}$ of $6^{\circ}-2^{\circ}$ and $2^{\circ}-0^{\circ}$ are selected for the hard alloy tool and the ceramics tool respectively; the cutting edge inclination angles of two types of tools mainly select $0^{\circ}$, which are not effectively optimized. more cutting edge inclination angles of below $0^{\circ}$ are selected, and the hard alloy tool and the ceramics tool occupy $74 \%$ and $66 \%$ respectively in negative angle selection proportion, and in case of selecting the smaller cutting edge inclination angle, the tool strength can be improved; the cutting edge inclination angle of below $0^{\circ}$ is more inclined to be selected for the ceramics tool due to brittleness to prevent vibration.

Tool cutting edge angle. Only by changing the tool cutting edge angle size can the proportion between the radial cutting force and the axial cutting force be adjusted; the larger the tool cutting edge angle is, the smaller the radial cutting force is, and the larger the axial cutting force is; the heat dissipation conditions [7 9] can be improved through adjusting the tool cutting edge angle. The diagram for selection law of tool cutting edge angles of two types of tools is shown as follows:

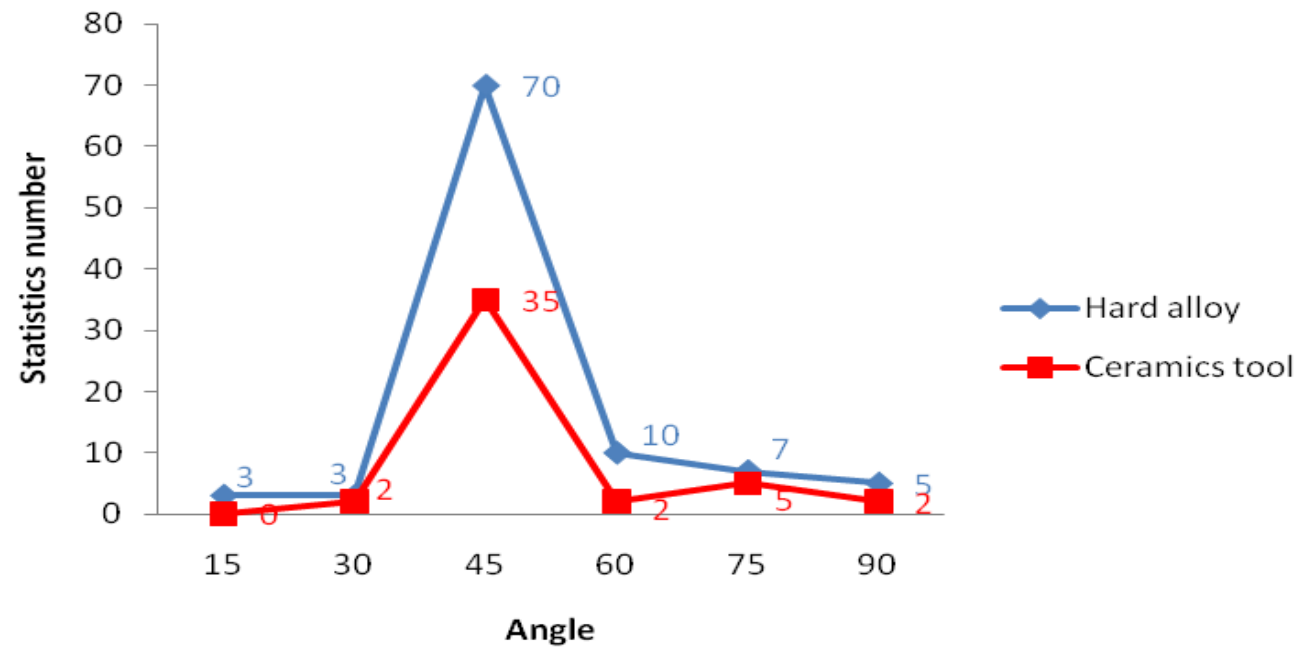

Fig. 5 Diagram for Selection Laws of Tool Cutting Edge Angles of Ceramics Tools for High-strength Material Machining

Through analyzing the law diagram, we can obtain that in high-strength material machining, the tool cutting edge angles $\mathrm{kr}$ of $45^{\circ}$ are mainly selected for two types of tools respectively, which shows that it is the most suitable for selecting the tool cutting edge angles of $45^{\circ}$, and the best 
cutting effect is realized as when the tool cutting edge angles of $45^{\circ}$ are selected, the increase of the radial cutting force can be avoided, the vibration can not be caused, and the heat radiation performance is good; other angles are not suitable for high-strength material machining.

\section{Conclusions}

Through summarizing machined tool materials and tool angles, the following results are obtained:

In high-strength material machining, due to better impact toughness, the hard alloy tool is one of the most applied tools; due to bad shock resistance, the ceramics tool is easy to break, of which the application scope is limited. The hard alloy tool and the ceramics tool respectively occupy $66.49 \%$ and $33.51 \%$ in use proportion.

The impact resistance of the tool can be reduced by the larger tool angle. As the hard alloy tool is better than the ceramics tool in impact resistance, the selection range of the hard alloy tool is wider than that of the ceramics tool during angle selection.

In order to ensure heat radiation as well as a certain hardness and sharpness, in relief angle selection, the relief angles of two types of tools are $6^{\circ}-10^{\circ}$ and are basically consistent with each other in selection law, and during this range, the two types of tools respectively occupy above 90 percent in use proportion.

In order to avoid no radial cutting force increase and no vibration and ensure good heat radiation conditions, the tool cutting edge angles $\mathrm{kr}$ of $45^{\circ}$ are mainly selected for two types of tools respectively.

The cutting edge inclination angles of $0^{\circ}$ are mainly selected for the two types of tools respectively, which are not optimized.

\section{References}

[1] Liu Wen'An, Ma Guangfeng and the like. EH360 Study on Machining of High-strength Steel [J]. Mechanical Engineer, 2000(3):49-51

[2] Liu Zhibing, Wang Xibin, Jie Lijing. High-speed Machining and Machining Example of Difficult-to-process Materials [J]. New Technology \& New Process, 2006:46-48

[3] Wang Yue, Liu Jia, Wang Xibin, Yang Hongjian. Experimental Study on High-strength Steel Dry Milling instead of Semi-Fine Grinding [J]. Tool Technology, 2004:24-26

[4] Ren Kaiqiang. Study on High-speed Milling of High-strength Titanium Alloy [J]. Master's Paper of Mechanical Manufacture and Automation Major of Nanjing University of Aeronautics and Astronautics, 2003:24-26

[5] Tu Shijie, Xu Jiwei and the like. Study on Dry Cutting and Near-dry Cutting of High-alloy Stainless Steel [J]. Mechanical Engineer, 2007:19

[6] Du Guochen. Machinability and Application of PCBN Tool [J]. Combined Machine Tool and Automated Processing Technology, 2004:95-96

[7] X.L.Liu,D.H.Wen,Z.J.Li.L.Xiao. Cutting Temperature and Tool Wear of Hard Turning Hardened Bearing Steel [J].Journal of Materials Processing Technology, 2002:200-206

[8] J.M.Zhou,H.Walter. Effect of Chamfer Angle on Wear of PCBN Cutting Tool [J]. Machine Tool \& Manufacture 2002:11

[9] Tonshoff H.K., Wobker H.G., Brandt D. Tool Wear and Surface Integrity in Hard Turning[J].Production Engineering, 1996:19-24 